\title{
The Potential Impact of Online/Distance Education for K-12 Special Education Students: A Meta-Analytic Investigation
}

\author{
Karen H. Larwin ${ }^{1}$, Matthew J. Erickson ${ }^{2}$ \\ ${ }^{1}$ Department of Educational Foundations, Research, Technology and Leadership, Youngstown State University, Youngstown, Ohio, USA \\ ${ }^{2}$ Department of Special Education, Slippery Rock University, Slippery Rock, Pennsylvania, USA
}

\section{Email address:}

khlarwin@ysu.edu (K. H. Larwin), matthew.erickson@sru.edu (M. J. Erickson)

\section{To cite this article:}

Karen H. Larwin, Matthew J. Erickson. The Potential Impact of Online/Distance Education for K-12 Special Education Students: A MetaAnalytic Investigation. International Journal of Elementary Education. Vol. 5, No. 1, 2016, pp. 8-16. doi: 10.11648/j.ijeedu.20160501.12

\begin{abstract}
The present meta-analysis is a comprehensive investigation of the effectiveness of online/distance educational opportunities on student achievement specifically for students with disabilities in grades K-12. An overall effect size of $d=-$ .015 was calculated from 7 studies for a total of 54 different effect size measures, based on a sample of data from $n=24,031$ participants. These results suggest that the achievement level of the typical students with disabilities did not differ from the achievement of students in the control group. However, further investigation indicates that students with disabilities experiencing online/distance education performed better than comparable students with disabilities who were in traditional face-to-face classrooms. Study demonstrates that sub-categories can be used to further the understanding of how the use of online/distance education could serve as one solution for shrinking the achievement gap for exceptional individuals. Implications and limitations are discussed.
\end{abstract}

Keywords: Online Education, Online Learning, Distance Education, K-12, Special Education, Meta-Analysis

\section{Introduction}

"Online courses and blended courses (combining online and face-to-face) have been used for more than a decade" in education (Francescucci \& Foster, 2013). As technology is developed to enhance the learning experience for students, schools are continually exploring strategies to implement new learning tools. These technological advancements have provided the opportunity for asynchronicity to transition from the norm for content delivery in online courses, now, combined with some synchronous tools, such as instant messaging software for feedback or questions, the virtual classroom more closely mimics the experience of face-toface classroom interaction (Francescucci \& Foster, 2013, Graham, 2013).

Distance education courses were initially designed to support educational opportunities to students who were limited due to geographic location or lifestyle to attend a face-to-face educational setting. The availability of online learning tools has provided flexibility and the opportunity to complete course requirements from nearly any location. According to Burton and Goldsmith (2002, p. 3), "the increased ease of communication between participants, greater equality of participation in the discussion, anonymity of participants, reduction in bias, ability to recruit diverse population, and the ability to address more controversial topics" are some of the advantages to distance education. In contrast, perceived disadvantages exist within the distance education arena. The "underrepresentation of the overall population because only internet users are included, loss of verbal cues during communication, potential privacy and confidentiality concerns, and a high no-show rate among participants agreeing but failing to participate in online forums" tend to be ongoing shortcomings in the online setting (Burton \& Bruening, 2003, p. 320). As technologies advance, some of these concerns are challenged with the development of emoticons and abbreviations to augment the lack of nonverbal and paraverbal cues in an online environment (Schneider, Kerwin, Frechtling, \& Vivari, 2002).

\subsection{Choice}

Expenses incurred by both colleges and universities, which ultimately impact the student in the form of fees and opportunity costs make the establishment of distance education models a financial risk. "Students would be attracted to less burdensome options if institutions were to 
offer more flexible approaches to study that have a lower cost of provision and hence lower fees" (Yuan, Powell, \& Oliver, 2014 , p. 5). The purchase, development, and implementation of online learning tools which include, a learning management system (LMS), as well as content storage and retrieval systems, email communication, document drop boxes, grade inquiries, discussion boars, learning objects and content, as well as online testing capabilities make the appearance of an online program intimidating to construct. However, these features are both attractive and welcomed changes to today's students who embrace the opportunity to work with technology to create a flexible mode of delivery. The introduction and implementation of online components into course delivery benefits both the schools, because of reduced costs, and the learner, through greater flexibility and convenience (Sadaghiani, 2011).

\subsection{Student Achievement}

A comprehensive review and meta-analysis conducted by Means, Yoyama, Murphy, Bakia, and Jones (2009) that focuses on online learning studies in North America, found that on average, students perform better when part, or all of their learning takes place in an online environment compared with students who are in traditional face-to-face conditions. When exploring what the differences are between distance education and traditional face-to-face educational programming for students, research conducted by Means et al. (2009), as well as Zhang, Zhou, Briggs, and Nunamaker (2006) suggest that the interactions between the instructor and student are ultimately what impacts learning. No significant difference is found when online quizzes and noninteractive video are available to students, however, simulations that prompt learner response and reflection yield positive outcomes. Just as in traditional face-to-face classrooms, when the instructional content limits the response requirements and does not tap in to higher order thinking skills, the output produced by the student is limited and not challenged. In an online synchronous or asynchronous setting, or in a face-to-face setting, the greatest outcomes can be reached when students are provided with an opportunity to interact and think critically.

However, some research suggests that distance education yields no notable impact on student achievement. Early blended offerings consisted of a traditional classroom approach with the addition of asynchronous online content. As technologies developed, both asynchronous, as well as synchronous, live online content was infused into instructional practices; however few studies control for the differences between treatment groups. Francescucci and Foster (2013) conducted a study that investigates the impact of teaching a blended course using a virtual, interactive, realtime, instructor-led (VIRI) classroom, on student engagement, performance, and satisfaction. Using an experimental design with a pre and post semester questionnaire, for ninety students at a large urban university, the study found no statistical differences in student performance between the control and the treatment groups.
The various features offered in blended courses make it difficult to compare outcomes. According to the results, the only statistical difference was between the groups is student interest in their courses. Francescucci and Foster find that fewer than 2 in 10 students express dissatisfaction with their participation in a VIRI course.

Likewise, Yong and Ping (2008) conducted a case study that included 14 academically at-risk primary students that were engaged in academic related tasks in an after school program that was mediated by a 3-D Multi-User Virtual Environment (MUVE). The results of this study found no significant difference in the students' academic performance; however, the students were found to be more engaged in the learning tasks and had acquired a range of information and communication technology skills. This unique opportunity enticed students to be interested in specific content areas and engaged them in learning using technology.

Studies utilizing online lectures and the face-to-face time, for interactive discussion, report significantly positive outcomes in student achievement (Dowling, Godfrey, \& Giles (2003). However, Burton and Goldsmith (2002) suggests the most significant factor that influenced the distance educational experience centered on "the importance of the role of faculty in facilitation successful online courses through effective communication with their students, presence online, and timely assessment of student work throughout the course" (p. 2). Flexibility in online courses, discipline necessary to be successful, and the importance of communication among students as a means to enhance the online learning environment and the importance of studentfocused support systems to foster a positive online learning experience were also listed as factors that emerged as significant to online learning environments. The individualized student-focused support systems and the flexibility provided by online /distance opportunities can provide promising options for students with disabilities.

A study conducted by John Richardson (2009) analyzed the role of being disabled as a factor in the attainment and experiences of over 2,300 distance-learning students awarded post-secondary degrees in the United Kingdom. Richardson's study highlighted problems at the collegiate level regarding disclosure of student disabilities in both the United Kingdom and the United States. The findings suggest that the attainment and overall experience of graduates who reported disabilities that they had not previously declared to the university were similar to those of graduates without a disability (Richardson, 2009).

Little research expands the investigation regarding the impact of online/distance education to the K-12 academic arena for students with disabilities. According to Habib, Berget Sandnes, Kahn, Fagernes, \& Olcay (2004) there has been "an increased focus on compensating for disabilities and ensuring universal access to the learning environment of students" (p. 574). Virtual learning environments have the "potential to extend equitable access to high-quality education to students from high-need urban and rural districts, low-achieving students, and students with 
disabilities" (Spitler \& Repetto, 2014, p. 4).

The virtual environment provides a delivery model that is suited perfectly to address the unique needs of at-risk learners that can "use technology tools as they gather, arrange, and present information to others to engage in inquiry, critical analysis, and synthesis in connecting the curriculum, with realworld problems" (Peterson \& Bond, 2004, p. 347). Students who have been distracted or deterred from learning due to their traditional school environment are "offered a welcomed break from the monotony of classroom instruction and have the opportunity to make choices about his or her learning" in virtual environments (Sivapunniam, 2009, p. 286).

In a recent report about the academic achievement of 4-12 grade online students in Pennsylvania demonstrated that students with disabilities performed significantly below students in the same online learning environments who were not identified as disabled (Larwin, 2013). This is consistent with other research examining the performance of students in different online learning environments, when examining achievement across those identified with and without disabilities (Englert, Zhao, Dunsmore, Collings, \& Wolbergs, 2014; Izzo, Yurick, Nagaraja, \& Novak, 2010; Savi, Savenye, \& Rowland, 2008). These results of all of these studies support the trend reported in national data suggesting that the achievement gap between students with and without disabilities is growing, in spite of many interventions intended to minimize these differences (NAEP, 2013). However, one study, Bodzin, Waller, Santoro, \& Kale (2007) suggests that students with disabilities actually performed better than students without, in an online biology course. While this research was limited to $n=89$ students, the findings suggest that the use of online curriculum can positively benefit student with disabilities when implementing an individualized student-focused approach to learning.

A better measure of the impact of online/distance learning for students with disabilities comes from research comparing student with disabilities in online learning environments relative to students with disabilities in traditional settings. A paucity of empirical research exists which examines this contrast and the few research studies that do exist present somewhat mixed results. Research by Englert et al., (2014) and Izzo, et al. (2010) both revealed mixed findings on the performance of students with and without disabilities, across a number of different measures of student knowledge. Both of these researchers examined the use of online learning environments to support a blended learning environment. Conversely, both Englert, Wu, \& Zhao, (2005) and Kim et al. (2006) found that students with disabilities in the online learning environment performed significantly higher on achievement measures than their peers receiving face-to-face instruction on the same content. These studies suggest that students benefited from the flexibility of the online learning opportunities.

In light of the mixed findings on the limited existing research, it is difficult to draw clear-cut conclusions about the impact of online/distance instruction on the achievement of students with disabilities. A meta-analysis of these studies would be an appropriate and effective approach to synthesizing and integrating the conflicting results from the existing quantitative research. This approach would provide a general measure of the impact of online instruction on student achievement for students with disabilities that might otherwise be obscured by the conflicting results. It also would be beneficial to an overall understanding of the impact of online instruction on students with disabilities by investigate how the impact on student achievement is affected by grade level, core discipline area, measurement type, and year of the investigation. The present project conducts such a meta-analysis.

\section{Method}

\subsection{Overview of Meta-Analysis}

The analytical method of choice for this study is a metaanalysis. A meta-analysis is a methodological approach in which data from multiple sources can be quantitatively synthesized in an effort to determine the overall effect of the phenomena of interest. Glass, McGaw, \& Smith, (1981) described meta-analysis as "Analysis of analyses". The purpose of the current meta-analytic application is to synthesize the data collected from multiple studies examining the impact of distance education participation by students identified as "special education". This analytic approach will make it possible to determine the significance of multiple variables against an outcome variable, specifically student achievement for the current investigation. Glass et al. (1981) explains that a meta-analysis allows for studies with smaller sample sizes to be combined, thus, producing a much larger sample size. This in turn will increase the statistical power and reliability of the estimates (Larwin, 2005).

Following the guidelines set forth by Glass et al. (1981), three steps were followed in conducting this meta-analytical study. First, existing research studies are collected to analyze against the outcome variable within each study. The studies collected fit the established parameters of the investigation, as well as, match the data of the specific research topic. It is likely that publication bias will be discovered while performing and analyzing the relevant studies. However, in order to minimize bias an exhaustive search was conducted for all available studies.

Next, the studies were reviewed, described, classified and coded. An important aspect of this step involves measurement consistency. Studies were coding by two different researchers, in order to establish rater agreement, which is essentially a score of homogeneity for the ratings. This process creates reliability of the coding processes in the data, and is found to be reliable in the classifications more than $95 \%$ of the time.

Lastly, the analysis was conducted which included computing an overall mean effect size measures, including each individual mean effect size measure for each research variable being studied. Once all the effect size measures were 
calculated, the results were analyzed, interpreted, and reported as findings. More specifically, a singular effect size measure was computed for all of the studies followed by individual effect size measures for each of the moderator variables.

\subsection{Research Questions}

The purpose of the current study is to examine the achievement of student's identified as "special education" who are participating in online learning (Treatment Group) relative to students who do not fit into this grouping. This "treatment" group's achievement will be compared to the achievement of student's identified as "special education" who do not participating in online learn (Control Group A). Additionally, treatment group student achievement will be compare to students' who are participating in online learning, but who are not identified as "special education" (Control Group B). In order to examine the multiple variables against the outcome variable of student achievement, data from the studies will be meta-analyzed to examine the following primary research questions:

1. Is academic achievement of the treatment group students different from the achievement of students in the control groups?

2. Is academic achievement of the treatment group students different from the achievement of students in the Control Group A?

3. Is academic achievement of the treatment group students different from the achievement of students in the Control Group B?

4. Is academic achievement of the treatment group students different from the achievement of students in the control group moderated by the student's grade level (elementary, middle school, high school)?

5. Is academic achievement of the treatment group students different from the achievement of students in the control group moderated by the discipline area of the learning (mathematics, reading, science, writing, technology)?

Secondary research questions will include:

6. Is academic achievement of the treatment group students different from the achievement of students in the control group moderated by the achievement measure used (local or state exam)?

7. Is academic achievement of the treatment group students different from the achievement of students in the control group moderated by the year of the study (2005-2013).

\subsection{Sample of Studies}

The studies for the current investigation will be found using electronic search engines at Youngstown State University. Specifically data bases such as: Academic Search Complete, ERIC, EBSCO, and Dissertation Abstracts. Searches will include data generated between 2005 and 2014. The search descriptors included such statements as: online education and special education students, distance education and special education students, and students with disabilities and technology. Summaries, abstracts, and table of contents of articles were reviewed in order to select which studies to examine more thoroughly. The inclusion criteria for the current investigation are:

1. Research studies that include students with disabilities in grades preK-12;

2. Research studies that include online learning or distance education;

3. Research studies that include comparison group members; and,

4. Research that include some form of student achievement data.

Articles were coded in an effort to address all proposed research questions. Student achievement data is used in the metric provided in the research, or it was decomposed for inclusion as needed. All the calculations for this investigation will be computed using Comprehensive Meta-Analysis (2009, CMA), a program designed for specifically conducting meta-analytic investigations.

\section{Results}

The initial search for studies relating to search key words and phrases revealed a total of 69 studies. After eliminating studies that did not focus on school-age students from Kindergarten through twelfth grade which included data from some form of achievement data, sixteen studies met the selection criteria. After setting the selection criteria to perform an analysis that specifically provides comparison data on student achievement data, seven studies met the criteria for analysis. These seven studies provided a total of fifty-four different effect-size measures, which include a total data sample size of $n=24,031$ participants.

The primary and secondary questions were used to identify the moderators that were coded and analyzed using CMA to determine if there was any significant effect of the characteristics of distance education on the student achievement of students with disabilities, and if so, what is the level of the effect across the various levels of the moderators. Specifically, the analyses examines (1) the achievement results for students with disabilities in online classes relative to all other student data, (2) the achievement results for students with disabilities in online/distance classes relative to the achievement results of similar students with disabilities in traditional face-to-face classes (Control Group A), and (3) the achievement results for students with disabilities in online/distance classes relative the achievement results for students in online/distance classes who are not identified as "special education" (Control Group B).

\subsection{Descriptive Analysis of Effect Sizes}

The primary purpose of this meta-analytic investigation was to investigate the impact online/distance education for students with disabilities on student achievement across a number of moderators. A comprehensive review of the 
literature produced seven studies that met the inclusion criteria. The effect size measures within the study range from -1.41 to 3.10 , yielding a grand mean overall effect size measure $d=-.015, p<.848$, a non-significant negative effect according to Cohen's (1992) guidelines for effect sizes. Cohen (1992) suggests the following guidelines most appropriate for use in social sciences interpretation of effect sizes: an effect size greater than 0.5 is considered large, an effect size at least 0.3 is considered medium and an effect size less than 0.1 is considered small. This result $(d=-.015)$ indicates that the there is no significant difference between the achievement results for students with disabilities in online classes relative to all other control group students achievement results, across the research studies included in this analysis. This effect size measure $(d=-.015)$ indicates that negligible differences between these two groups of students.

Twenty-eight of the 54 effect sizes $(51.8 \%)$ that were used in this study were negative which implies that control group students performed better, whereas thirty-one $(48.1 \%)$ were positive indicating students in the treatment group performed better. The analyses also reveals that $37(68.5 \%)$ of the 54 effect size measures had a mean effect size of 0.5 or greater, an effect on student achievement according to Cohen (1992) were considered large. The results of additional analyses are presented in Table 1.

Table 1. Overall Moderators and Level Results.

\begin{tabular}{|c|c|c|c|}
\hline Variables and Categories & $\begin{array}{l}\text { Number of } \\
\text { Effect Size } \\
\text { Measures } \\
\end{array}$ & $\begin{array}{l}\text { With-In } \\
\text { Groups } \\
\text { Effects }\end{array}$ & $\begin{array}{l}\text { Mean } \\
\text { Effect } \\
\text { Size }\end{array}$ \\
\hline Comparison & & $-.034 *$ & \\
\hline $\begin{array}{l}\text { Special Ed Online vs Special Ed } \\
\text { Traditional (Treatment Group vs } \\
\text { Control Group A) } \\
\text { Special Ed Online vs Non-Special }\end{array}$ & 24 & & $.497 *$ \\
\hline $\begin{array}{l}\text { Ed Online (Treatment Group vs } \\
\text { Control Group B) }\end{array}$ & 30 & & $-.561 *$ \\
\hline Core Discipline & & $-.093 *$ & \\
\hline Mathematics & 9 & & $-.718^{*}$ \\
\hline Reading & 13 & & $-.461 *$ \\
\hline Science & 11 & & -.111 \\
\hline Writing & 15 & & $.545^{*}$ \\
\hline Technology & 6 & & .300 \\
\hline Grade Level & & $-.619^{*}$ & \\
\hline Elementary & 26 & & .162 \\
\hline Middle School & 9 & & $-.812 *$ \\
\hline High School & 19 & & -.501 \\
\hline Assessment Measure Type & & $-.190 *$ & \\
\hline Local & 35 & & $.373 *$ \\
\hline State Testing & 19 & & $-.752 *$ \\
\hline Publication Year & & $-.619 *$ & \\
\hline 2005 & 2 & & $1.548^{*}$ \\
\hline 2006 & 5 & & .842 \\
\hline 2007 & 22 & & .207 \\
\hline
\end{tabular}

\begin{tabular}{llll}
\hline Variables and Categories & $\begin{array}{l}\text { Number of } \\
\text { Effect Size } \\
\text { Measures }\end{array}$ & $\begin{array}{l}\text { With-In } \\
\text { Groups } \\
\text { Effects }\end{array}$ & $\begin{array}{l}\text { Mean } \\
\text { Effect } \\
\text { Size }\end{array}$ \\
\hline 2008 & 2 & .750 \\
2010 & 8 & -.338 \\
2011 & 4 & -.711 \\
2012 & 4 & -.621 \\
2013 & 7 & -.832 \\
\hline
\end{tabular}

As indicated in Table 1, analyses examining if there is a differential impact on student achievement when examining the studies comparing (1) special education students using online instruction relative to special education students who did not utilize online instruction, to the existing research that compared (2) special education students using online instruction relative to non-special education students also using online instruction, indicate that there is a significant difference across these two groups $(p>.05)$. Specifically, results indicate that students with disabilities perform significantly better in online/distance learning classes than similar groups of special education students in traditional face-to-face instruction on measures of student achievement $(d=.497)$. This suggests a large positive impact for the use of online/distance education for students with disabilities.

Conversely, students with disabilities perform significantly poorer in online/distance learning classes comparatively to similar groups of students who are not identified as special education but who took the same online/distance learning classes $(d=-.561)$. More importantly is more comprehensive examination of the impact online of education for students with disabilities relative to Control Group A and Control Group B separately.

Analysis of Control Group A studies reveals the greatest positive impact of online educational delivery for students with disabilities is indicated with a large significant effect in both reading $(d=.936)$ and writing $(d=.535)$ achievement. Additionally, results indicate that a positive effect is seen across all grade levels, with data for students in elementary school showing a large significant effect $(d=.630)$. Also notable are large positive significant effects that are revealed for each data publication year from 2005-2008.

Analysis of Control Group B studies reveals the greatest positive impact of online educational delivery for students with disabilities is indicated with a large significant effect in technology course $(d=.895)$ achievement. However, results indicate that a negative effect is seen across all grade levels, with data for students in middle school showing a largest significant effect $(d=-.774)$. This finding suggests that students who are not identified as special education are performing better in the online/distance delivery educational mode when compared to students identified as special education. Also notable are large negative significant effects that are revealed for each data publication year from 2008-2013. The complete results for the comparisons for both Control Group A and Control Group B are presented in Table 2. 
Table 2. Grouped Moderators Effect Size Measures.

\begin{tabular}{|c|c|c|c|c|}
\hline \multirow[b]{2}{*}{$\begin{array}{l}\text { Variables and } \\
\text { Categories }\end{array}$} & \multicolumn{2}{|c|}{$\begin{array}{l}\text { Control Group A } \\
\text { (Special Ed Not Online) }\end{array}$} & \multicolumn{2}{|c|}{$\begin{array}{l}\text { Control Group B (Non- } \\
\text { Special Ed Online) }\end{array}$} \\
\hline & $\begin{array}{l}\text { Number of } \\
\text { Effect Size } \\
\text { Measures }\end{array}$ & $\begin{array}{l}\text { Mean } \\
\text { Effect } \\
\text { Size } \\
\end{array}$ & $\begin{array}{l}\text { Number of } \\
\text { Effect Size } \\
\text { Measures }\end{array}$ & $\begin{array}{l}\text { Mean } \\
\text { Effect } \\
\text { Size } \\
\end{array}$ \\
\hline \multicolumn{5}{|l|}{ Core Discipline } \\
\hline Mathematics & - & - & 9 & $-0.718 *$ \\
\hline Reading & 4 & $0.936^{*}$ & 9 & $-0.821 *$ \\
\hline Science & - & - & 11 & -0.158 \\
\hline Writing & 15 & $0.535^{*}$ & - & - \\
\hline Technology & 5 & 0.191 & 1 & $0.895^{*}$ \\
\hline \multicolumn{5}{|l|}{ Grade Level } \\
\hline Elementary & 18 & $0.630^{*}$ & 8 & $-0.740 *$ \\
\hline Middle School & 1 & 0.494 & 8 & $-0.774 *$ \\
\hline High School & 5 & 0.194 & 14 & $-0.225 *$ \\
\hline \multicolumn{5}{|l|}{ Measure Type } \\
\hline Local & 24 & $0.408^{*}$ & 11 & 0.077 \\
\hline State Testing & - & - & 19 & $-0.752 *$ \\
\hline \multicolumn{5}{|l|}{$\begin{array}{l}\text { Data Publication } \\
\text { Year }\end{array}$} \\
\hline 2005 & 2 & $1.548^{*}$ & - & - \\
\hline 2006 & 5 & $0.844 *$ & - & - \\
\hline 2007 & 12 & $0.426^{*}$ & 10 & -0.048 \\
\hline 2008 & 1 & $0.478^{*}$ & 1 & $0.895^{*}$ \\
\hline 2010 & - & - & 4 & $-0.763 *$ \\
\hline 2011 & 4 & 0.157 & 4 & $-0.720^{*}$ \\
\hline 2012 & - & - & 4 & $-0.644 *$ \\
\hline 2013 & - & - & 7 & $-0.820 *$ \\
\hline
\end{tabular}

\subsection{Publication Bias}

Publication bias is a concern when performing a metaanalysis, and a criticism of the meta-analytic approach (Hunter \& Schmidt, 2004). Publication bias occurs when studies that find positive significant results for the effect being investigated are more likely to be published than studies that do not find significant findings therefore making it more likely that these studies will be included in metaanalytic investigations. Publication bias has the potential of inflating the effect size estimates (Hedges, 1986). Egger's Test of the Intercept was used to further assess the presence of publication bias in the current investigation. For the current investigation, Egger's test reveals that the intercept is $3.96, \mathrm{CI}_{95}[2.97,4]$, .95with $\mathrm{t}(52)=8.02, \mathrm{p}=0.001$. The significant results indicate that publication bias is a concern with the current group of research studies. However, visual examination of the data reveals that bias is in a negative direction, in that a preponderance of the effect size measures included in this investigation revealed negative effects, as seen in Figure 1.

In the absence of any bias, the effect size measure points are evenly scattered within the plot. As indicated in Figure 1, a group effect size points are forming a funnel effect in the negative hemisphere, approximately between zero and negative one. This type of bias while significant, does not bias the results in a positive direction.

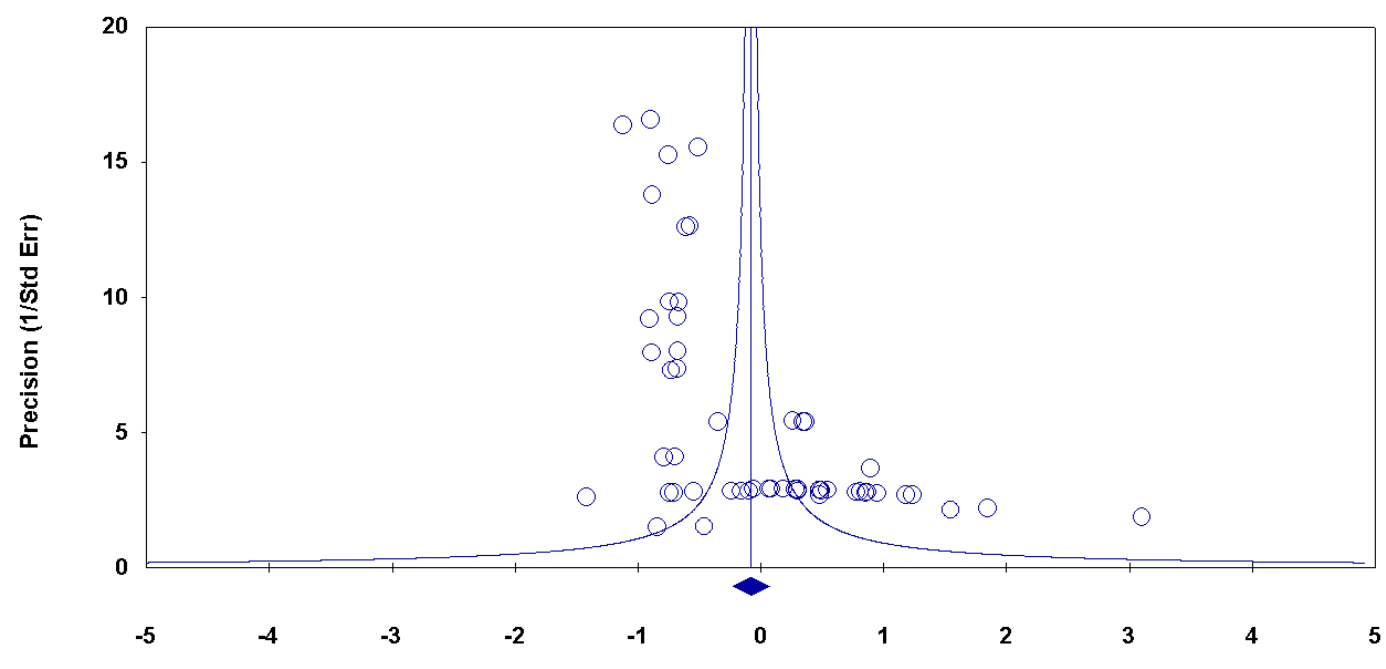

Figure 1. Funnel Plot of Precision of Effect Size Measures.

\section{Discussion}

The current investigation sought to examine the impact on online/distance learning on students with disabilities. This investigation examined this impact by meta-analyzing existing research on the academic achievement of disabled students in various online learning conditions relative to similar disabled students receiving the same instruction in a traditional face-to- face delivery, as well as to similar non-disabled students who were receiving the same online instruction. Results suggest that students with disabilities participating in online/distance education performed significantly better on many academic measures when compared to similar disabled students receiving the same instruction in a traditional format. Conversely, students with disabilities performed significantly poorer than non-disabled students participating in the same online/distance education delivery. 
The first finding of this investigation suggests that students with disabilities may benefit from online/distance education options. The results are derived from a research sample of $n$ $=3558$ students with disabilities. These findings indicated that students with disabilities in the online/distance learning sections outperformed at all grade levels and in all topic areas (reading, writing, and technology). These effect size measures are significantly large, suggesting elevated performance levels of 15 to 33 percentile points (Cohen, 1992). This is the first known study to demonstrate a large significant effect for students of disabilities in online learning environments using meta-analytic techniques. Unfortunately, there is no known existing research that compares the performance of these two groups in mathematics or science.

The second finding validates the existing research on the academic achievement of students with disabilities relative to other students (NAEP, 2013). The National Assessment of Educational Progress (NAEP) describes the educational achievement levels of students with disabilities as "dismal". The achievement gap that has traditionally existed between disabled students and other students, according to the 2013 report is growing. The findings of the current investigation support the supposition. Students identified as disabled performed significantly lower than their non-disabled counterparts across all grade levels and in all core curricula areas. While this is not the focus of this investigation, there are implications from these findings for those who develop and deliver online education to disabled populations. Since the first finding of this research suggests that students with disabilities in the online/distance learning environment are excelling over the students with disabilities who are in comparable face-to-face environments, this suggests that online/distance learning opportunities offer students with disabilities a learning environment that is more conducive to their personal challenges.

Meehan, Cowley, Schumacher, Hauser, \& Croom (2003) research suggests that with less time dedicated toward administrative routines, and more time dedicated on instruction student-led activities, effective management and monitoring techniques, that achievement gaps can be reduced for students with disabilities. Online/distance educational opportunities can provide students with these needed educational benefits. Bodzin, et al. s (2007) study purported contradictory findings. This research demonstrated that students with disabilities in their population performed better on the online learning component of their biology classes. However, their use of online/distance education was used to supplement information in a blended delivery format.

The moderator of grade level followed the same pattern as the first and second research findings. Non-disabled students demonstrated small to large significantly higher effect size measures over students with disabilities in the same online/distance education classes across all grade levels. Consistently, students with disabilities in online/distance education demonstrated small to large significantly higher effect size measures over students with disabilities in the similar face-to-face sections. This same pattern of results was demonstrated across the core curriculum areas. Unfortunately, there is very little rigorous research on the effectiveness of online learning focused on K-12 students and even less research on the impact online instruction for students with disabilities (Graham, 2013; Meehan, et al., 2003; NCD, 2004; USDE, 2010). According to the USDE report, most of the research found that adult learners performed better in the online instructional arenas; and online instruction in which there was ongoing collaboration and monitoring by the facilitator - as opposed to independent learning - demonstrated the greatest impact. It also suggests that the five studies on the efficacy of online instruction, four of which included blended instruction, provided promise for this delivery in the K-12 arena.

Also notable are the results regarding form of measurement. For the comparison between the type of achievement results of students with disabilities, online and not online, local achievement results demonstrated a moderate significant effect. For the same comparison between the achievement of students with disabilities online relative to students with no disabilities online, results suggest a large significant effect found with state level achievement measures. While it may be argued that state level achievement measures are likely more standardized measures, these are not often considered to be a good measure of student achievement (Thomas, 2013). Secondly, many students with disabilities do not consistently participate in state level measures, with our without accommodations (NCD, 2004).

\section{Limitations}

There were number of limitations associated with this research study. A number of individual studies are small for the current sample of studies. Although this might have occurred as the result of an insufficient computer literature search strategy, that was not the case for the current investigation. The literature search process was thorough and exhaustive and turned up a number of additional empirical research studies not included in the past meta-analytic reviews of this subject area. As indicated above, the result is that there are relatively few studies that look at online learning within the K-12 arena and with students with disabilities.

Another limitation of the present study is associated with meta-analytic studies in general. It can be the case with the meta-analytic approach that it is difficult to break categories down enough to examine as much information as possible without creating too much overlap in the results. Although these overlaps in categories can be used as a form of "triangulation" and a reliability check, they can also cause redundancy and useless repetition. However, a benefit to the meta-analytic process is that synthesize data from a number of studies on the same topic provides for larger sample sizes than are generally found in single studies. These larger sample sizes increase the reliability of the research findings (Glass, et al. 1981). Also with the meta-analytic approach, the meta-analytic researcher is at the mercy of the authors who have conducted research in the area. The researcher has 
to rely on the authors or individual researchers to report results accurately, describe the studies well, report statistics appropriately, and respond to inquiries about their research if there are any questions or discrepancies.

The current state of education for students with disabilities demands action. According the most recent nation reports, the gap that exists between students with and without disabilities is growing, in spite of efforts to create a more conducive educational environment for this population of exceptional individuals (NAEP, 2013). The results of the current investigation provide some hope to the dark cloud that hangs over the impact of special education today. With increasing options for online and blended curriculum, today like no time in history, educators and parents are equipped with choices that can maximize the learning of students with disabilities. As the results of this meta-analytic study, based on a sample of data from 3,558 students with disabilities, demonstrates, online and blended opportunities can be used to supplement and enhance the educational experiences of students with disabilities, potentially increasing their overall performance as much as 13-33 percentile points. These kinds of results would eliminate half of the currently existing achievement gap existing between the achievement results of students with and without disabilities (NAEP, 2013). While more research is needed, across all arenas of K-12 online instruction (Graham, 2013), and across different core areas of instruction, this research provides insight to one readily available medium of educational delivery that can disproportionally impact our exceptional individuals.

\section{References}

[1] Bodzin, A. M., Waller, P. L., Santoro, L. E., \& Kale, D. (2007). Investigating the use of inquiry and web-based activities with inclusive biology learners. The American Biology Teacher, 69(5), 273-279.

[2] Burton, L. J. \& Bruening J. E. (2003) Technology and methodology intersect in the on-line focus group. Quest, 55 (4), 315-327.

[3] Burton, L, \& Goldsmith, D. (2002). Students' experiences in online course: A study using asynchronous online focus groups. Report presented to the Connecticut Distance Learning Consortium. Retrieved from http://www.ctdlc.org/ResourceDocs/evaluation/StudentExperi ence.pdf

[4] Cohen, J. (1992). "A power primer". Psychological Bulletin 112 (1): 155-159. New York University. Retrieved December 18, 2012 from http://web.vu.lt/fsf/d.noreika/files/2011/10/Cohen-J-1992-Apower-primer-kokio-reikia-imties-dyd $\% \mathrm{C} 5 \%$ BEio.pdf

[5] Comprehensive Meta-Analysis. (2009). Retrieved October 20, 2009, from http://www.metaanalysis.com

[6] Dowling, C., Godfrey, J. M., \& Gyles, N. (2003). Do hybrid flexible delivery teaching methods improve accounting students' learning outcomes? Accounting Education, 12, 373391.
[7] Egger, M., Smith, G. D., Schneider, M., \& Minder, C. (September 1997). "Bias in meta-analysis detected by a simple, graphical test". BMJ, 315 (7109): 629-624.

[8] Englert, C. S., Wu, X., Zhao, Y. (2005). Cognitive tools for writing: Scaffolding performance of students through technology. Learning Disabilities Research \& Practice, 20(3), 184-198.

[9] Englert, C. S., Zhoa, Y., Dunsmore, K., Collings, N. Y., \& Wolbres, K. (2014). Learning Disability Quarterly, 30(1), 929.

[10] Francescucci, A., \& Foster, M. (2013). The VIRI classroom: the impact of blended synchronous online course on student performance, engagement, and satisfaction. Canadian Journal of Higher Education, 43(3), 78-91.

[11] Glass, G. V., McGaw, B., \& Smith, M. L. (1981). Metaanalysis I social research. London: Sage Publications.

[12] Graham, C. R. (2013). Emerging practice and research in blended learning. In M. G. Moore (Ed.), Handbook of distance education (3rd ed., pp. 333-350). New York, NY: Routledge.

[13] Habib, L., Berget, G., Sandnes, F. E., Sanderson, N., Kahn, P., Fagernes, S., \& Olcay, A. (2012). Dyslexic students in higher education and virtual learning environments: An exploratory study. Journal of Computer Assisted Learning, doi: 10.1111/j.1365-2729.2012.00486.x.

[14] Hedges, L. V. (1983). A random effects model for effect sizes. Psychological Bulletin, 93, 388-395.

[15] Hunter, J. E., \& Schmidt, F. L. (2004). Methods of metaanalysis: Correcting error and bias in research findings $\left(2^{\text {nd }}\right.$ edition). Newbury Park, CA: Sage. Hillsdale, NJ.

[16] Izzo, M. V., Yurick, A., Nagaraja, H. N., \& Novak, J. A. (2010). Effects of a $21^{\text {st }}$-Century curriculum on students information technology and transition skills. Career Development for Exceptional Individuals. 33(2), 95-105.

[17] Kim, A., Vaughn, S., Klingner, J. K., Woodruff, A. L., Reutebuch, C. K., \& Kouzekanani, K. (2006). Improving the reading comprehension of middle school students with disabilities through computer-assisted collaborative strategic reading. Remedial and Special Education, 27(4), 235-249.

[18] Larwin, K. H. (2005). The impact of computer-assisted instruction on student achievement in post-secondary statistics education: A meta-analysis. (Unpublished Master's Thesis, Kent State University).

[19] Larwin, K. H. (2013, April). Examining academic impacts of online education on special education populations: 2010-2013 results from publically Pennsylvania State Educational Data. Presentation to the Western Pennsylvania school administrators.

[20] Means, B., Toyama, Y., Murphy, R., Bakia, M., \& Jones, K. (2009). U. S. Department of Education, Office of Planning, Evaluation, and Policy Development, Evaluation of EvidenceBased Practices in Online Learning: A Meta-Analysis and Review of Online Learning Studies, Washington, D. C.

[21] Meehan, M. L., Cowley, K. S., Schumacher, D., Hauser, B., \& Croom, N. D. M. (2003, July). Classroom environment, instructional resources, and teaching differences in highperforming Kentucky schools with achievement gaps. Charleston, WV: AEL, Inc. 
[22] NCD (2004). Improving Educational Outcomes for Students with Disabilities. Retrieved from http://www.educationalpolicy.org/pdf/ncd.pdf

[23] NAEP (2013). Policy Insider: Council for Exceptional Children. Retrieved from http://www.policyinsider.org/2013/11/naep-results-showwide-achievement-gaps-between-students-with-withoutdisabilities.html

[24] Peterson, C., L., \& Bond, N. (2004). Online compared to faceto-face teacher preparation for learning standards-based planning skills. Journal of Research on Technology in Education, (36)4, 345-347.

[25] Richardson, J. T. E. (2009). The attainment and experiences of disabled students in distance education. Distance Education, 30(1), 87-88.

[26] Sadaghiani, H. R. (2011). Using multimedia learning modules in a hybrid-online course in electricity and magnetism. Physical Education Research, doi: 10.1103/PhysRevSTPER.7.010102.

[27] Savi, C. O., Savenye, W., \& Rowland, C. (2008). The effects of implementing web accessibility standards on the success of secondary adolescents. Journal of Educational Multimedia and Hypermedia, 17(3), 387-411.

[28] Schneider, S., Kerwin, J., Frechtling, J., \& Vivari, B. (2001). Characteristics of the discussion. in online and face-to-face focus groups. Social Science Computer Review, 20(1). 31-42.

[29] Spitler, C., Repetto, J., \& Cavanaugh, C. (2013). Investigation of a Special Education Program in a Public Cyber Charter School, American Journal of Special Education, doi: 10.1080/08923647.2013.754182, 27(1), 4-15.

[30] Sivapunniam, N. (2009). Virtual realities: a blended learning approach to bridge the gap between diverse ESL learners. Retrieved August 28, 2014, from http://www.ukm.my/solls09/Proceeding/PDF/nackeeran.pdf

[31] Thomas, E. (2013) A meta-analytic investigation examining effective characteristics of professional development in k-12 education since the inception of the no child left behind act of 2002. (Unpublished doctoral dissertation, Youngstown State University).

[32] U. S. Department of Education (2010). Evaluation of Evidence-Based Practices in Online Learning: A MetaAnalysis and Review of Online Learning Studies, Retrieved from www.ed.gov/about/offices/list/opepd/ppss/reports.html.

[33] Yuan, L., Powell, S., \& Oliver, B. (2014). Beyond MOOCs: Sustainable online learning in institutions. Center for Educational Technology, Interoperability, and Standards. Retrieved from http://publications.cetis.ac.uk/2014/898

[34] Yong, T. L., \& Ping, L. C. (2008) Engaging academically at risk primary school students in an ICT mediated after school program. Australasian Journal of Educational Technology, 24(5), 521-539.

[35] Zhang, D., Zhou, L., Briggs, R. O., \& Nunamaker, J. F. (2006). Instructional video in e-learning: Assessing the impact of interactive video on learning effectiveness. Information and Management, 43, 15-27. 